\title{
The selectivity of hydrazine oxidation on a polycrystalline rhodium surface
}

\author{
Jagdish Prasad and John L. Gland \\ Department of Chemistry, The University of Michigan, Ann Arbor, MI 48109-1055, USA
}

Received 28 November 1990; accepted for publication 6 May 1991

The surface reactions of coadsorbed hydrazine and atomic oxygen have been examined by means of temperature-programmed reaction spectroscopy (TPRS) on a clean polycrystalline rhodium surface over the 90 to $1450 \mathrm{~K}$ temperature range. Nitrogen and water are the primary oxidation products observed. In addition, the usual hydrazine decomposition products $\mathrm{N}_{2}, \mathrm{NH}_{3}, \mathrm{H}_{2}$ and $\mathrm{N}_{2} \mathrm{H}_{2}$ are observed. Nitrogen oxides (NO and $\mathrm{N}_{2} \mathrm{O}$ ) were not observed even in the presence of excess oxygen. Preadsorbed atomic oxygen initiates hydrazine oxidation below $140 \mathrm{~K}$ indicating that adsorbed hydrazine is quite reactive on a clean rhodium surface. Large initial coverages of coadsorbed hydrazine and atomic oxygen result in the formation of nitrogen and water below $200 \mathrm{~K}$. We suggest that the $\mathrm{N}-\mathrm{N}$ bond in hydrazine remains intact resulting in "direct" $\mathrm{N}_{2}$ formation during this low-temperature oxidation process. An analogous "direct" $\mathrm{N}_{2}$ formation process has been previously reported during hydrazine decomposition on iridium; we have also reported a similar process during hydrazine decomposition on rhodium. For lower hydrazine coverages, two higher temperature water desorption peaks at 270 and $360 \mathrm{~K}$ are observed. The water peak at $270 \mathrm{~K}$ is limited by reaction of $\mathrm{H}, \mathrm{O}$ and $\mathrm{OH}$ while the water peak at $360 \mathrm{~K}$ appears $t o$ be limited by surface reaction between coadsorbed oxygen and a $\mathrm{NH}_{y}$ surface intermediate. With increasing initial oxygen coverages the yield of water increases, while the yield of hydrazine decomposition products $\left(\mathrm{NH}_{3}, \mathrm{H}_{2}\right.$ and $\mathrm{N}_{2} \mathrm{H}_{2}$ ) decreases. The selectivity of nitrogen formation during hydrazine oxidation below $250 \mathrm{~K}$ is controlled by direct reaction processes which leaves the $\mathrm{N}-\mathrm{N}$ bond in hydrazine intact. In this temperature range, hydrogen-oxygen reactions are the dominant mode of interaction with the adsorbed atomic oxygen. Above $250 \mathrm{~K}$, nitrogen-nitrogen recombination is strongly favored over a broad range of temperatures and coverages. No evidence for a nitrogen-oxygen surface was observed even in the presence of excess adsorbed oxygen clearly suggesting the predominance of $\mathrm{N}$ atom recombination over $\mathrm{N}+\mathrm{O}$ atom surface reaction even in the presence of excess adsorbed atomic oxygen.

\section{Introduction}

This study of hydrazine oxidation is part of a program to characterize the surface chemistry and reactions of adsorbed hydrazine on a wide range of solid surfaces. Hydrazine oxidation on rhodium surfaces may furnish an interesting perspective on simple oxidation processes involving adsorbed $\mathrm{N}_{x} \mathrm{H}_{y}$ species which may be important during ammonia oxidation. Hydrazine is a effective reducing agent which is widely used to selectively hydrogenate unsaturated organic reagents in the liquid phase. Hydrazine oxidation with air at room temperature proceeds spontaneously necessitating anaerobic handling procedures to guard against potential spontaneous combustion. Hydrazine de- composition on metal surfaces is a rapid exothermic process which led to the development of effective low-temperature monopropellant systems currently used in satellites and high-altitude aircraft.

A number of investigators have characterized the adsorption and decomposition of hydrazine on metal surfaces [1-11]. An extensive study of hydrazine decomposition by Sawin and Merrill focussed on the mechanisms and dynamics of hydrazine decomposition on the $\operatorname{Ir}(111)$ surface [10]. Angular resolved TPD studies of hydrazine decomposition have been used to obtain information about decomposition mechanisms and the geometries of the kinetically active surface species. The low-temperature decomposition products are 
strongly peaked along the surface normal indicating that the desorbing decomposition products leave with a substantial amount of energy from the decomposition reaction in their translational degree of freedom normal to the surface. Simultaneous formation of the decomposition products along with their strongly forward peaked angular distributions led the authors to conclude that low-temperature pathways were due to direct reaction on the surface [10]. Vibrational spectroscopy has been used to characterize an adsorbed $\mathrm{NH}$ species formed during hydrazine decomposition on the Ni(111) surface [9]. This NH intermediate is stable up to $450 \mathrm{~K}$ [9].

We have recently characterized hydrazine decomposition on this same $\mathrm{Rh}$ foil surface using temperature-programmed desorption [1]. The gasphase products observed during hydrazine decomposition on a $\mathrm{Rh}$ foil surface depend markedly on the initial hydrazine coverage. At low coverage, nitrogen and hydrogen are the only products observed indicating complete decomposition has occurred. At high coverage (near monolayer), nitrogen, hydrogen, ammonia and diimide are all observed during the decomposition reaction. For high coverages, direct decomposition is suggested by simultaneous desorption of ammonia and nitrogen at $220 \mathrm{~K}$. An analogous "direct" $\mathrm{N}_{2}$ formation process has been previously reported during hydrazine decomposition on iridium by Sawin and Merril [10]. The high-temperature nitrogen peak at
$635 \mathrm{~K}$ corresponds to the recombination of atomic nitrogen formed during the decomposition process. Initial high hydrazine coverages results in a weakly bound molecular desorption peak of hydrazine which desorbs at $220 \mathrm{~K}$.

\section{Experimental}

The experiments were performed in a UHV system equipped with Auger electron spectroscopy (AES), low-energy electron diffraction (LEED) and a multiplexed mass spectrometer for temperature-programmed reaction spectroscopy (TPRS) [1]. The base pressure after bakeout was $3.2 \times$ $10^{-11}$ Torr. The rhodium foil was mounted on a manipulator which allowed resistive heating to $1500 \mathrm{~K}$ and cooling to approximately $80 \mathrm{~K}$. The temperature was monitored by a chromel-alumel thermocouple spot-welded to the back of the sample. The sample was cleaned by repeated heating to $800 \mathrm{~K}$ in $2 \times 10^{-7}$ Torr of oxygen and by argon ion bombardment. The TPRS data were recorded with a linear temperature ramp of $10 \mathrm{Ks} \mathrm{s}^{1}$. The sample was placed $2 \mathrm{~mm}$ from the mass spectrometer collimator in direct line-of-sight to reduce background effects and eliminate contributions from support wires.

All gases were adsorbed at $80 \mathrm{~K}$ through a doser approximately $2.5 \mathrm{~cm}$ away from the surface. Hydrazine and oxygen were dosed through two

Table 1

Hydrazine oxidation products on a clean $\mathrm{Rh}$ foil surface and their desorption temperatures for various oxygen coverages dosed with low and high hydrazine exposures

\begin{tabular}{|c|c|c|c|c|c|c|c|}
\hline \multirow{2}{*}{$\begin{array}{l}\text { Exposure } \\
\mathrm{O}_{2}(\mathrm{~L})\end{array}$} & \multirow{2}{*}{$\begin{array}{l}\mathrm{N}_{2} \mathrm{H}_{4} \\
\text { expo- } \\
\text { sure }\end{array}$} & \multicolumn{6}{|c|}{ Hydrazine oxidation products and their desorption peak temperature } \\
\hline & & $140-200 \mathrm{~K}$ & $220-270 \mathrm{~K}$ & $220-500 \mathrm{~K}$ & $290-360 \mathrm{~K}$ & $460 \mathrm{~K}$ & $600-700 \mathrm{~K}$ \\
\hline 0.0 & low & & & & $\mathrm{H}_{2}$ & $\mathrm{H}_{2}$ & $\mathrm{~N}_{2}$ \\
\hline 0.2 & low & $\mathrm{N}_{2}$ & $\mathrm{~N}_{2}, \mathrm{H}_{2} \mathrm{O}$ & & $\mathrm{H}_{2}, \mathrm{H}_{2} \mathrm{O}$ & $\mathrm{H}_{2}$ & $\mathrm{~N}_{2}$ \\
\hline 0.3 & low & $\mathrm{N}_{2}$ & $\mathrm{~N}_{2}, \mathrm{H}_{2} \mathrm{O}$ & & $\mathrm{H}_{2}, \mathrm{H}_{2} \mathrm{O}$ & $\mathrm{H}_{2}$ & $\mathrm{~N}_{2}$ \\
\hline 0.6 & low & $\mathrm{N}_{2}$ & $\mathrm{~N}_{2}, \mathrm{H}_{2} \mathrm{O}$ & & $\mathrm{H}_{2}, \mathrm{H}_{2} \mathrm{O}$ & $\mathrm{H}_{2}$ & $\mathrm{~N}_{2}$ \\
\hline 1.0 & low & $\mathrm{N}_{2}$ & $\mathrm{~N}_{2}, \mathrm{H}_{2} \mathrm{O}$ & & $\mathrm{H}_{2} \mathrm{O}$ & & $\mathrm{N}_{2}$ \\
\hline 0.0 & high & & $\mathrm{N}_{2}, \mathrm{NH}_{3}$ & $\mathrm{~N}_{2} \mathrm{H}_{2}$ & $\mathrm{H}_{2}$ & $\mathbf{H}_{2}$ & $\mathrm{~N}_{2}$ \\
\hline 0.2 & high & $\mathrm{H}_{2} \mathrm{O}$ & $\mathrm{N}_{2}, \mathrm{NH}_{3}, \mathrm{H}_{2} \mathrm{O}$ & $\mathrm{N}_{2} \mathrm{H}_{2}$ & $\mathrm{H}_{2}$ & $\mathrm{H}_{2}$ & $\mathrm{~N}_{2}$ \\
\hline 0.3 & high & $\mathrm{H}_{2} \mathrm{O}$ & $\mathrm{N}_{2}, \mathrm{NH}_{3}, \mathrm{H}_{2} \mathrm{O}$ & $\mathrm{N}_{2} \mathrm{H}_{2}$ & $\mathrm{H}_{2}^{2}$ & $\mathrm{H}_{2}$ & $\mathrm{~N}_{2}$ \\
\hline 0.6 & high & $\mathrm{N}_{2}, \mathrm{H}_{2} \mathrm{O}$ & $\mathrm{N}_{2}, \mathrm{NH}_{3}, \mathrm{H}_{2} \mathrm{O}$ & $\mathrm{N}_{2} \mathrm{H}_{2}$ & $\mathrm{H}_{2}$ & $\mathbf{H}_{2}$ & $\mathrm{~N}_{2}^{2}$ \\
\hline 1.0 & high & $\mathrm{N}_{2}, \mathrm{H}_{2} \mathrm{O}$ & $\mathrm{N}_{2}, \quad \mathrm{H}_{2} \mathrm{O}$ & & $\mathrm{H}_{2}$ & $\mathrm{H}_{2}$ & $\mathrm{~N}_{2}^{2}$ \\
\hline
\end{tabular}


separate dosers. The hydrazine doser was preconditioned carefully and hydrazine was changed frequently to minimize decomposition inside the doser. The details of hydrazine dosing are discussed in ref. [1]. In these oxidation experiments, the $\mathrm{Rh}$ foil surface was first exposed to oxygen gas at $80 \mathrm{~K}$. The sample was heated to $200 \mathrm{~K}$ to remove molecular oxygen from the surface. The sample was then cooled to $80 \mathrm{~K}$ and dosed with hydrazine. A series of five representative atomic oxygen coverages (fig. 1) were reacted with both high and low hydrazine coverages (fig. 2) to establish the selectivity of hydrazine oxidation as a function of the reactant coverages. The results of hydrazine oxidation are summarized in table 1.

\section{Results}

Typical oxygen desorption spectra for the representative series of five atomic oxygen coverages used in these $\mathrm{N}_{2} \mathrm{H}_{4}$ oxidation studies are shown in fig. 1.

Desorption spectra generated following adsorption of low and high coverages of hydrazine (no coadsorbed atomic oxygen) are shown in figs. 2 and 3 respectively. For coverages substantially smaller than a monolayer, adsorbed hydrazine decomposes completely (fig. 2) on a clean rhodium surface during a TPRS cycle. The gas-phase prod-

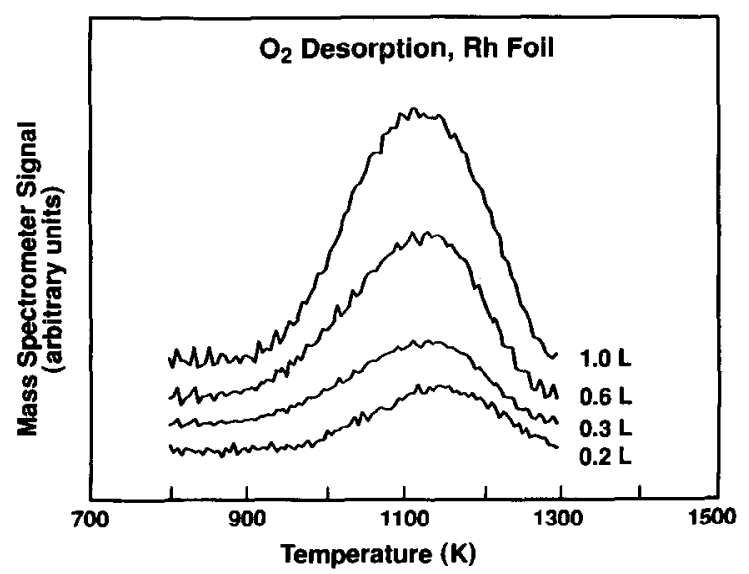

Fig. 1. Thermal desorption spectra of oxygen from a Rh foil surface. Oxygen is adsorbed at $80 \mathrm{~K}$ and heated to $200 \mathrm{~K}$ to remove molecular oxygen from the surface.

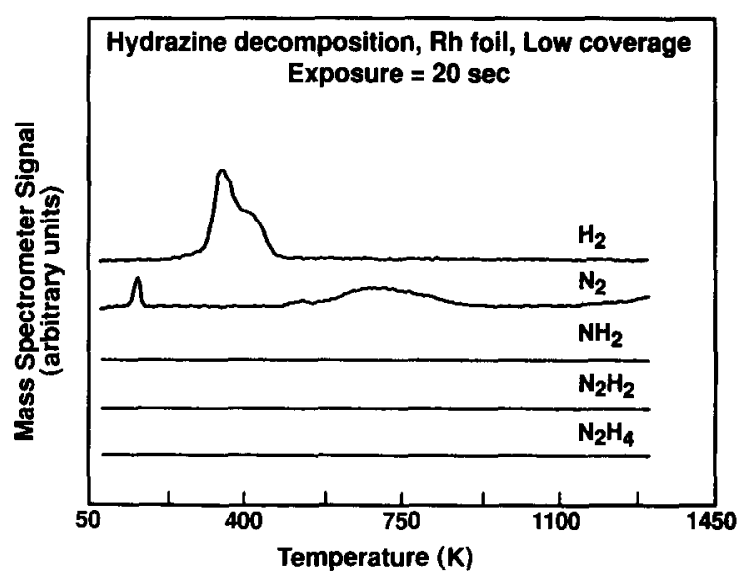

Fig. 2. A TPRS spectrum illustrating the complete dissociation of hydrazine adsorbed at $80 \mathrm{~K}$ on a clean $\mathrm{Rh}$ foil surface. $\mathrm{N}_{2}$ and $\mathrm{H}_{2}$ are the only desorbing species observed. The heating rate was $10 \mathrm{~K} / \mathrm{s}$.

ucts observed are $\mathrm{H}_{2}\left(T_{\mathrm{p}}=360 \mathrm{~K}\right.$ and $T_{\mathrm{p}}=460$ K) and $\mathrm{N}_{2}\left(T_{\mathrm{p}}=635 \mathrm{~K}\right)$ only. Increasing hydrazine coverage results in the formation of $\mathrm{NH}_{3}$ and $\mathrm{N}_{2} \mathrm{H}_{2}$ in addition to the low-coverage products $\left(\mathrm{H}_{2}\right.$ and $\mathrm{N}_{2}$ ) (fig. 3). Ammonia has two desorption peaks at 220 and $360 \mathrm{~K}$ for high coverages of $\mathrm{N}_{2} \mathrm{H}_{4}$ (fig. 3). The nitrogen peak at $635 \mathrm{~K}$ shifts to lower temperature and a new peak at 220 $\mathrm{K}$ appears as the hydrazine coverage increases (fig. 3). Diimide formation is observed above $220 \mathrm{~K}$

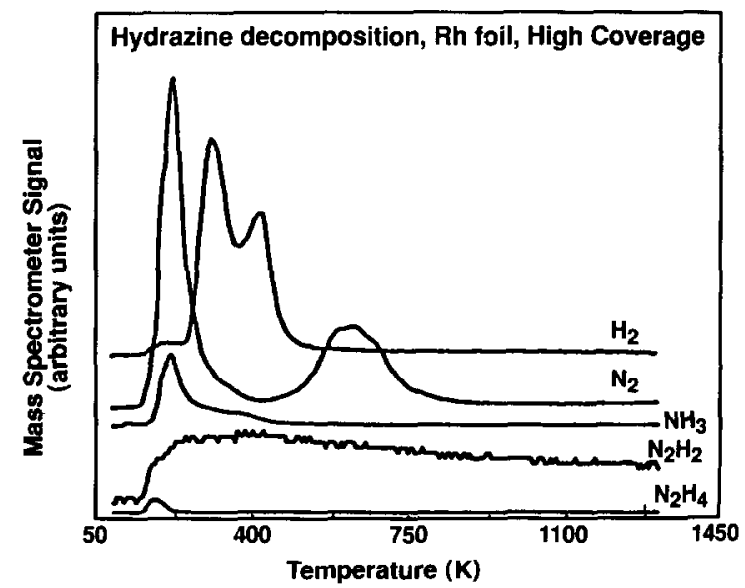

Fig. 3. A TPRS spectrum illustrating the dissociation of hydrazine adsorbed at $80 \mathrm{~K}$ on a clean $\mathrm{Rh}$ foil surface at high coverage. $\mathrm{N}_{2}, \mathrm{H}_{2}, \mathrm{NH}_{3}, \mathrm{~N}_{2} \mathrm{H}_{4}$ are the desorbing species observed. The heating rate was $10 \mathrm{~K} / \mathrm{s}$. 


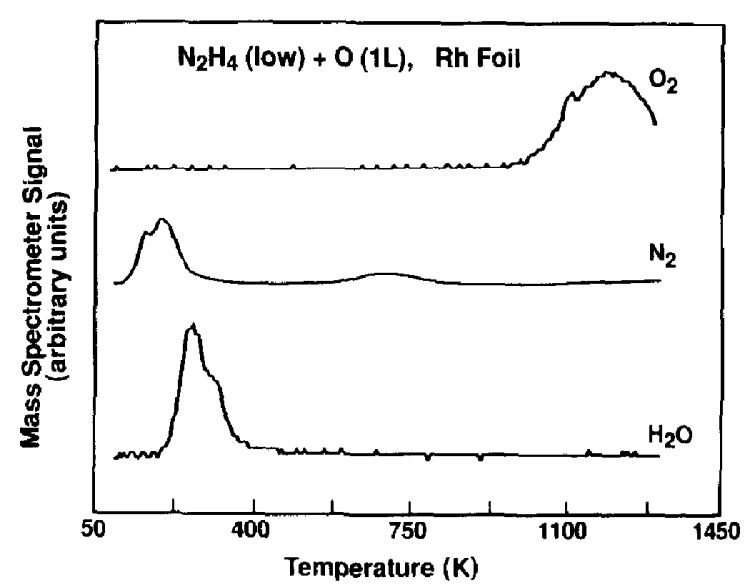

Fig. 4. Thermal desorption spectra of $\mathrm{H}_{2} \mathrm{O}, \mathrm{N}_{2}$, and excess $\mathrm{O}_{2}$ during $\mathrm{N}_{2} \mathrm{H}_{4}$ oxidation on a clean $\mathrm{Rh}$ foil surface for $1 \mathrm{~L}$ of atomic oxygen exposure coadsorbed with low hydrazine exposure.

(fig. 3). High initial hydrazine coverages result in formation of a weakly bound $\mathrm{N}_{2} \mathrm{H}_{4}$ molecular desorption peak at $220 \mathrm{~K}$ (fig. 3). For a more complete discussion of $\mathrm{N}_{2} \mathrm{H}_{4}$ decomposition see ref. [1].

For low initial coverages of hydrazine coadsorbed with atomic oxygen on a $\mathrm{Rh}$ foil surface, two water peaks at 270 and $360 \mathrm{~K}$ (fig. 4) and two low-temperature nitrogen desorption peaks at 140 and $220 \mathrm{~K}$ (fig. 4) were observed in addition to the expected hydrazine decomposition products (fig.

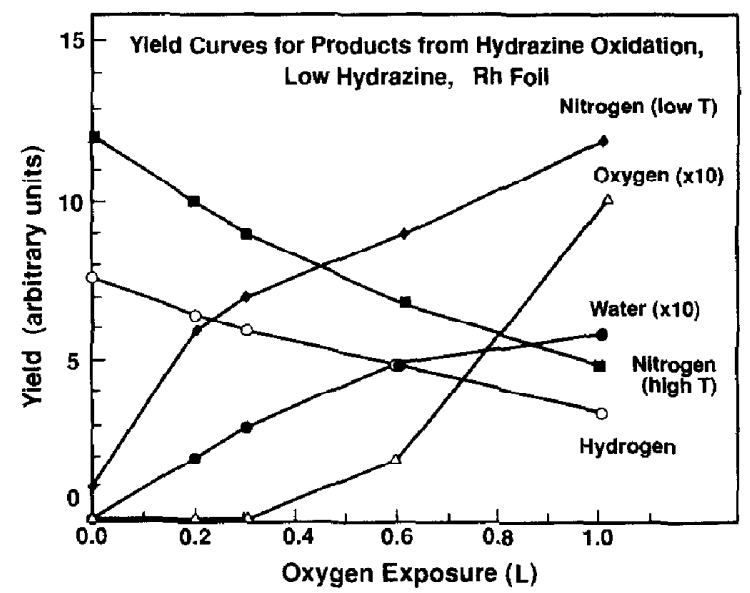

Fig. 5. Yield curves for hydrazine oxidation products $\mathrm{H}_{2}, \mathrm{H}_{2} \mathrm{O}$, $\mathrm{N}_{2}$, and $\mathrm{O}_{2}$ as a function of predosed oxygen exposures coadsorbed with low hydrazine exposure.

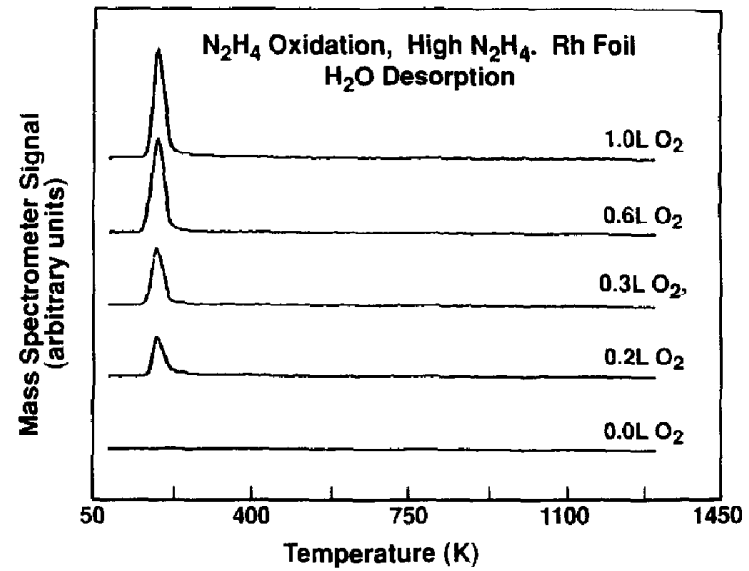

Fig. 6. Thermal desorption spectra of $\mathrm{H}_{2} \mathrm{O}$ during $\mathrm{N}_{2} \mathrm{H}_{4}$ oxidation on a clean $\mathrm{Rh}$ foil surface for various exposures of oxygen coadsorbed with high $\mathrm{N}_{2} \mathrm{H}_{4}$ exposure.

2). The water desorption peak at $270 \mathrm{~K}$ increases with increasing coverage of oxygen, while the water peak at $360 \mathrm{~K}$ decreases. Yields for all the products of hydrazine (low coverage) reaction with coadsorbed atomic oxygen on a Rh foil surface are shown in fig. 5.

For high initial hydrazine coverages coadsorbed with oxygen, water desorbs at $190 \mathrm{~K}$ (fig. 6). The yield of the low-temperature water peak increases with increasing oxygen coverage. The low-temperature nitrogen peak at $140 \mathrm{~K}$ also increases with

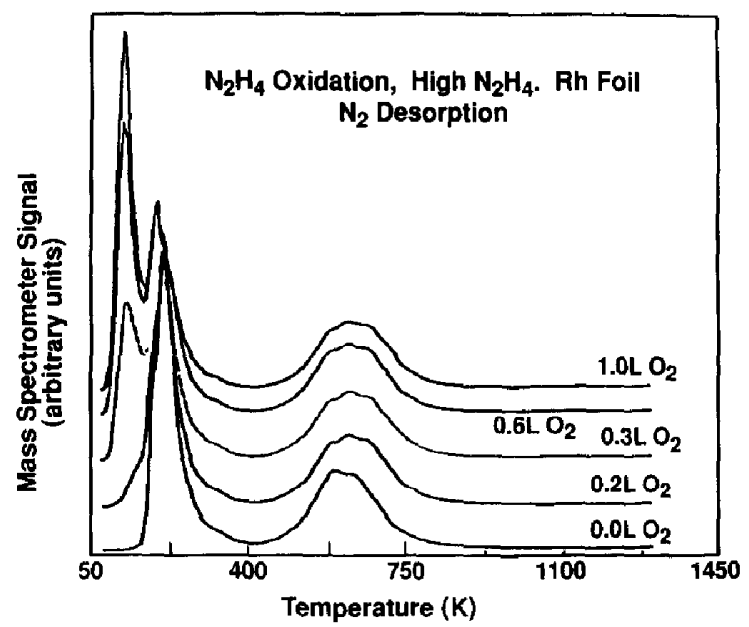

Fig. 7. Thermal desorption spectra of $\mathrm{N}_{2}$ during hydrazine oxidation for various exposures of oxygen coadsorbed with high hydrazine exposure. 


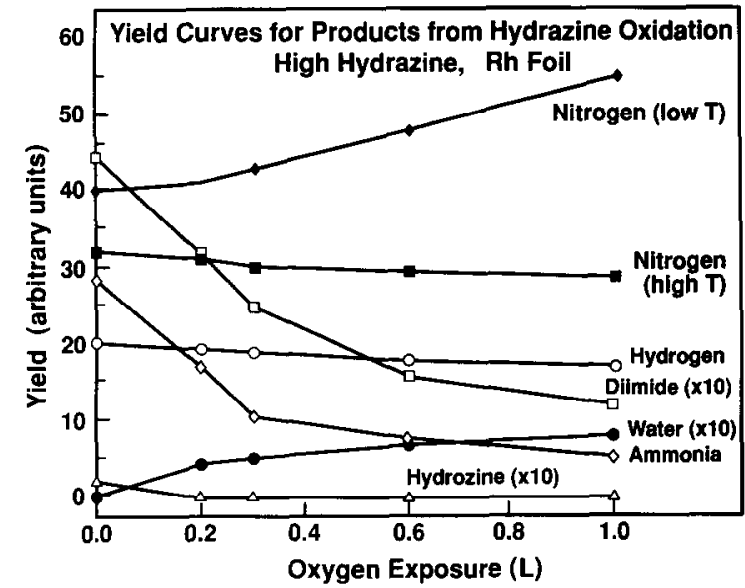

Fig. 8. Yield curves for hydrazine oxidation products $\mathbf{H}_{2}$, $\mathrm{NH}_{3}, \mathrm{H}_{2} \mathrm{O}, \mathrm{N}_{2} \mathrm{H}_{2}$, and $\mathrm{N}_{2}$ as a function of oxygen exposures for high exposure of hydrazine.

increasing atomic oxygen coverages, while the nitrogen peak at $635 \mathrm{~K}$ decreases (figs. 7 and 8 ). The yields of hydrogen, $\mathrm{NH}_{3}$ and diimide decrease with increasing coverage of oxygen (fig. 8).

\section{Discussion}

Nitrogen and water are the primary products of hydrazine oxidation on rhodium. Oxygen-containing nitrogen products ( $\mathrm{NO}$ and $\mathrm{N}_{2} \mathrm{O}$ ) were not observed even in the presence of excess coadsorbed atomic oxygen. Preadsorbed atomic oxygen initiates hydrazine oxidation below $140 \mathrm{~K}$ indicating that adsorbed hydrazine is quite reactive on a clean polycrystalline $R h$ surface. During these TPD studies of hydrazine oxidation we observe that decomposition competes with oxidation reactions over a large range of coverages and temperatures. The yields of the $\mathrm{N}_{2}$ and $\mathrm{H}_{2} \mathrm{O}$ oxidation products increase with increasing oxygen coverage, while the yields of ammonia, hydrogen and diimide (the decomposition products) decrease as oxygen coverages increase. The details of low- and high-coverage hydrazine surface oxidation are discussed separately in the next two sections. The final section of the discussion is focussed on the selectivity of this surface oxidation reaction.

\subsection{Low hydrazine coverage}

Low coverages of adsorbed hydrazine (no coadsorbed oxygen) decompose completely on a clean $R h$ surface during a TPRS cycle since only gas-phase $\mathrm{H}_{2}$ and $\mathrm{N}_{2}$ desorb from the surface (fig. 2). A single nitrogen recombination peak is observed at $635 \mathrm{~K}$ for low hydrazine coverages (fig. 2 ). This peak is clearly caused by atomic nitrogen recombination as indicated by comparison with previous results reported in the literature for atomic nitrogen recombination on polycrystalline $\mathrm{Rh}$ surfaces [5]. Two hydrogen desorption peaks are observed at 360 and $460 \mathrm{~K}$ during decomposition of low-coverage hydrazine (fig. 2). The hydrogen peak at $360 \mathrm{~K}$ is identical to the desorptionlimited peak observed following hydrogen adsorption on the $\mathrm{Rh}$ surface, indicating the formation of adsorbed atomic hydrogen below the hydrogen desorption temperature of $360 \mathrm{~K}$. The hydrogen desorption peak at $460 \mathrm{~K}$ is limited by thermal dehydrogenation of a hydrogen-containing surface intermediate which we previously suggested is $\mathrm{NH}$ [1].

Reaction of low hydrazine coverages with a series of oxygen coverages results in formation of two water desorption peaks at 270 and $360 \mathrm{~K}$ (fig. 4). The peak at $270 \mathrm{~K}$ is not desorption-limited since the reference water desorption peak from the $\mathrm{Rh}$ surface occurs at $180 \mathrm{~K}$ [12]. Gurney and Ho [13] have reported that from the reaction of $\mathrm{O}$ and $\mathrm{H}$ on the $\mathrm{Rh}(100)$ surface water desorbs at $275 \mathrm{~K}$. Thus we believe that in this hydrazine oxidation reaction on the $R h$ surface a water desorption peak at $270 \mathrm{~K}$ occurs as a result of $\mathrm{O}$ and $\mathrm{H}$ reaction via $\mathrm{OH}$ according to

$$
\begin{aligned}
& \mathrm{H}(\mathrm{ad})+\mathrm{O}(\mathrm{ad}) \stackrel{\text { below } 270 \mathrm{~K}}{\longrightarrow} \mathrm{OH}(\mathrm{ad}), \\
& \mathrm{OH}(\mathrm{ad})+\mathrm{OH}(\mathrm{ad}) \stackrel{270 \mathrm{~K}}{\longrightarrow} \mathrm{H}_{2} \mathrm{O}(\text { gas })+\mathrm{O}(\mathrm{ad}) .
\end{aligned}
$$

The water desorption peak at $360 \mathrm{~K}$ appears to be reaction-limited. The water desorption peak resulting from ammonia oxidation appears at $270 \mathrm{~K}$ [4]. Thus the water peak at $360 \mathrm{~K}$ observed during hydrazine oxidation cannot be caused by ammonia oxidation. At this time we are unable to determine the exact mechanism of the peak at 360 
$\mathrm{K}$ but suggest that oxidation of a stable surface intermediate $(\mathrm{NH})$ may be involved. Two lowtemperature nitrogen desorption peaks at 140 and $220 \mathrm{~K}$ are observed for low coverages of hydrazine reacting with coadsorbed oxygen (fig. 4). We believe that the peak at $140 \mathrm{~K}$ is due to a direct oxidation reaction and occurs according to $\mathrm{N}_{2} \mathrm{H}_{4}$ $+\mathrm{O}$ (below $140 \mathrm{~K}$ ) $\rightarrow \mathrm{N}_{2}$ (gas) $+\mathrm{H}_{2} \mathrm{O}(\mathrm{ad})$. We suggest that the hydrogen from hydrazine may be directly transferred to an adjacent adsorbed oxygen atom in analogy with a previous suggestion involving direct hydrogen transfer to adjacent $\mathrm{N}_{x} \mathrm{H}_{y}$ species during hydrazine decomposition [10]. The nitrogen peak at $220 \mathrm{~K}$ is due to direct decomposition of hydrazine on the $\mathrm{Rh}$ surface as reported previously [1]. For low initial hydrazine exposure, nitrogen does not desorb at $220 \mathrm{~K}$ (fig. 2 ) in the absence of coadsorbed oxygen. This result suggests that the adsorbed atomic oxygen may indirectly increase the surface reactivity and causes direct decomposition according to $\mathrm{N}_{2} \mathrm{H}_{4}$ $(220 \mathrm{~K}) \rightarrow \mathrm{N}_{2}$ (gas) $+\mathrm{H}$ (ad). In the case of ammonia oxidation on the same surface, no low-temperature pathway $(140 \mathrm{~K})$ for $\mathrm{N}_{2}$ formation was observed [4]. A comparison of hydrazine oxidation with ammonia oxidation data [4] on the same $R h$ foil surface indicates that the low-temperature $\mathrm{N}_{2}$ pathways are characteristic of $\mathrm{N}_{2} \mathrm{H}_{4}$ oxidation on the $\mathrm{Rh}$ surface. The yield curves for the products for low hydrazine coverages (fig. 5) show that water and nitrogen yields increase with increasing coverage of oxygen while the yield of hydrogen decreases.

Thus for low initial coverages of hydrazine coadsorbed with oxygen, we propose the following mechanism for hydrazine oxidation:

low-temperature oxidation

$\mathrm{N}_{2} \mathrm{H}_{4}+\mathrm{O} \stackrel{140 \mathrm{~K}}{\longrightarrow} \mathrm{N}_{2}$ (gas) $+\mathrm{OH}(\mathrm{ad})$

direct decomposition

$\mathrm{N}_{2} \mathrm{H}_{4} \stackrel{220 \mathrm{~K}}{\longrightarrow} \mathrm{N}_{2}$ (gas) $+\mathrm{H}(\mathrm{ad})$

$\mathrm{H}(\mathrm{ad})+\mathrm{O}(\mathrm{ad}) \stackrel{140 \mathrm{~K}}{\longrightarrow} \mathrm{OH}(\mathrm{ad})$

recombination

$\mathrm{OH}(\mathrm{ad})+\mathrm{OH}(\mathrm{ad}) \stackrel{270 \mathrm{~K}}{\longrightarrow} \mathrm{H}_{2} \mathrm{O}(\mathrm{gas})+\mathrm{O}(\mathrm{ad})$ dissociative adsorption

$\mathrm{N}_{2} \mathrm{H}_{4} \stackrel{220 \mathrm{~K}}{\longrightarrow} \mathrm{NH}(\mathrm{ad})+\mathrm{N}(\mathrm{ad})+\mathrm{H}(\mathrm{ad})$

recombination

$\mathrm{H}(\mathrm{ad})+\mathrm{H}(\mathrm{ad}) \stackrel{360 \mathrm{~K}}{\rightarrow} \mathrm{H}_{2}$ (gas)

dissociation of surface intermediate

$\mathrm{NH}(\mathrm{ad}) \stackrel{460 \mathrm{~K}}{\longrightarrow} \mathrm{N}(\mathrm{ad})+\mathrm{H}_{2}$ (gas)

recombination

$\mathrm{N}(\mathrm{ad})+\mathrm{N}(\mathrm{ad}) \stackrel{635 \mathrm{~K}}{\longrightarrow} \mathrm{N}_{2}$ (gas).

This mechanism is consistent with the data in table 1 for low initial coverage of hydrazine coadsorbed with oxygen on a $\mathrm{Rh}$ foil surface

\subsection{High hydrazine coverages}

Decomposition of a high coverage of $\mathrm{N}_{2} \mathrm{H}_{4}$ (no coadsorbed oxygen) is shown in fig. 3 . Two hydrogen desorption peaks are observed at 360 and 460 $\mathrm{K}$, while ammonia and nitrogen desorb simultaneously at $220 \mathrm{~K}$. As discussed earlier, Sawin and Merril have studied the angular dependence of similar low-temperature nitrogen and ammonia peaks on the $\operatorname{Ir}(111)$ surface [10]. From the angular dependence of the peaks and simultaneous formation of reaction products, Sawin and Merril [10] concluded that the low-temperature peak is produced by the direct decomposition of adsorbed hydrazine species. They suggest direct transfer of hydrogen from hydrazine to an adsorbed $\mathrm{N}_{x} \mathrm{H}_{y}$ species resulting in simultaneous $\mathrm{N}_{2}$ and $\mathrm{NH}_{3}$ formation [10]. During our recent hydrazine decomposition studies on rhodium we observed simultaneous low-temperature formation of ammonia and nitrogen suggesting that a similar direct decomposition mechanism may dominate at low temperature [1].

Coadsorbed atomic oxygen and hydrazine react on a Rh surface below $200 \mathrm{~K}$. Water (fig. 6) and nitrogen (fig. 7) are the primary low-temperature reaction products. We suggest that the $\mathrm{N}-\mathrm{N}$ bond in hydrazine remains intact resulting in "direct" $\mathrm{N}_{2}$ formation during this low temperature process. This hypothesis is supported by the observation that reaction between coadsorbed ammonia and 
atomic oxygen on this same surface does not result in low-temperature nitrogen formation. Thus this low temperature reaction is clearly characteristic of hydrazine oxidation on a $\mathrm{Rh}$ foil surface. This low-temperature reaction may involve direct transfer of hydrogen from the hydrazine to adjacent coadsorbed oxygen atoms. This process may be analogous to the direct decomposition process proposed earlier which involves direct transfer of a hydrogen from adsorbed hydrazine to an adjacent adsorbed $\mathrm{N}_{x} \mathrm{H}_{y}$ species [10].

$$
\mathrm{N}_{2} \mathrm{H}_{4}+2 \mathrm{O} \stackrel{\text { below } 200 \mathrm{~K}}{\longrightarrow} \mathrm{N}_{2} \text { (gas) }+2 \mathrm{H}_{2} \mathrm{O} \text { (gas). }
$$

Yields of water and nitrogen increase with increasing oxygen exposure while the yields of hydrogen, ammonia, and diimide decrease as expected (fig. 8). For high coverages of $\mathrm{N}_{2} \mathrm{H}_{4}$, only a single water peak at $190 \mathrm{~K}$ has been observed. The usual desorption-limited peak for water occurs at $180 \mathrm{~K}$. Thus the water peak at $190 \mathrm{~K}$ is desorption-limited. This peak indicates the formation of adsorbed water below $190 \mathrm{~K}$.

Thus for high hydrazine coverage coadsorbed with atomic oxygen on a $\mathrm{Rh}$ foil surface the results presented in figs. $6-8$ and summarized in table 1 lead us to postulate the following mechanism for $\mathrm{N}_{2} \mathrm{H}_{4}$ oxidation:

Low-temperature direct oxidation

$\mathrm{N}_{2} \mathrm{H}_{4}+\mathrm{O} \stackrel{140 \mathrm{~K}}{\longrightarrow} \mathrm{N}_{2}$ (gas) $+\mathrm{H}_{2} \mathrm{O}($ ad)

desorption

$$
\mathrm{H}_{2} \mathrm{O}(\mathrm{ad}) \stackrel{190 \mathrm{~K}}{\longrightarrow} \mathrm{H}_{2} \mathrm{O}(\text { gas })
$$

direct decomposition

$$
\begin{aligned}
& \mathrm{N}_{2} \mathrm{H}_{4} \stackrel{220 \mathrm{~K}}{\longrightarrow} \mathrm{N}_{2} \text { (gas) }+\mathrm{H}(\mathrm{ad}) \\
& \mathrm{N}_{2} \mathrm{H}_{4}+\mathrm{H}(\mathrm{ad}) \stackrel{220 \mathrm{~K}}{\longrightarrow} \mathrm{NH}_{3} \text { (gas) }
\end{aligned}
$$

dissociative adsorption

$$
\mathrm{N}_{2} \mathrm{H}_{4} \stackrel{220 \mathrm{~K}}{\longrightarrow} \mathrm{NH}(\mathrm{ad})+\mathrm{N}(\mathrm{ad})+\mathrm{H}(\mathrm{ad})
$$

dissociation of surface intermediate

$\mathrm{NH}(\mathrm{ad}) \stackrel{460 \mathrm{~K}}{\longrightarrow} \mathrm{N}(\mathrm{ad})+\mathrm{H}_{2}$ (gas) hydrogenation

$\mathrm{NH}(\mathrm{ad})+2 \mathrm{H}(\mathrm{ad}) \stackrel{360 \mathrm{~K}}{\longrightarrow} \mathrm{NH}_{3}$ (gas)

recombination

$\mathrm{NH}(\mathrm{ad})+\mathrm{NH}(\mathrm{ad}) \stackrel{\text { above } 220 \mathrm{~K}}{\longrightarrow} \mathrm{N}_{2} \mathrm{H}_{2}$ (gas)

$\mathrm{N}(\mathrm{ad})+\mathrm{N}(\mathrm{ad}) \stackrel{635 \mathrm{~K}}{\longrightarrow} \mathrm{N}_{2}$ (gas)

$\mathrm{H}(\mathrm{ad})+\mathrm{H}(\mathrm{ad}) \stackrel{360 \mathrm{~K}}{\longrightarrow} \mathrm{H}_{2}$ (gas)

Angular resolved TPD studies may provide more information about direct reaction pathways and the geometries of the kinetically active surface species. We hope to perform a series of angular dependent studies of $\mathrm{N}_{2}$ and $\mathrm{H}_{2} \mathrm{O}$ desorption during $\mathrm{N}_{2} \mathrm{H}_{4}$ oxidation in order to investigate the nature of low-temperature pathways and the geometries of the active species on the surfaces in the future.

\subsection{Selectivity}

Two distinct reaction pathways for nitrogen formation are observed during hydrazine oxidation on this Rh surface. Wc expect that hydrazinc oxidation selectivity will be controlled by different factors in these two regions. Below $250 \mathrm{~K}$ nitrogen formation is dominated by direct reaction processes which leaves the $\mathrm{N}-\mathrm{N}$ bond in hydrazine intact. In this temperature range, hydrogen-oxygen reactions are the dominant mode of interaction with the adsorbed atomic oxygen. Above $250 \mathrm{~K}$ adsorbed atomic nitrogen and atomic oxygen are the dominant surface species for large initial atomic oxygen coverages. Therefore we expect nitrogen-nitrogen-oxygen surface reactions to compete, yielding molecular nitrogen and nitrogen oxides, respectively. Our results clearly indicate that on this rhodium surface nitrogennitrogen recombination is strongly favored over a broad range of temperatures and coverages. No evidence for nitrogen-oxygen surface reactions was observed even in the presence of excess adsorbed atomic oxygen.

In contrast to hydrazine oxidation, no low-temperature pathways are observed either for nitrogen or water formation during ammonia oxidation on 
the same $\mathrm{Rh}$ surface [4]. These ammonia oxidation results clearly suggest that reaction pathways below $250 \mathrm{~K}$ are characteristic of hydrazine oxidation only. Nitrogen formation during ammonia oxidation is clearly dominated by nitrogen-nitrogen recombination at higher temperatures $(670 \mathrm{~K})$. A number of previous studies on both supported and unsupported rhodium catalysts have reported nitrogen-nitrogen recombination as primary pathway in agreement with our results. These results are in contrast with the results on the $\mathrm{Pt}(111)$ surface where NO formation has been observed [14].

\section{Conclusions}

In summary, the selectivity of hydrazine oxidation on a Rh foil surface has been studied by means of temperature-programmed reaction spectroscopy. Nitrogen and water are found to be the primary products of hydrazine oxidation at $140 \mathrm{~K}$. Oxygen-containing nitrogen products (NO and $\mathrm{N}_{2} \mathrm{O}$ ) were not observed even in the presence of excess oxygen. Preadsorbed atomic oxygen initiates hydrazine oxidation below $140 \mathrm{~K}$ indicating that adsorbed hydrazine is quite reactive on a clean polycrystalline Rh surface. Large initial coverages of coadsorbed hydrazine and atomic oxygen resulted in the formation of water and nitrogen at temperatures below $200 \mathrm{~K}$. 'The yields of $\mathrm{N}_{2}$ and $\mathrm{H}_{2} \mathrm{O}$ oxidation products increase with increasing oxygen coverage while the yields of decomposition products (ammonia, hydrogen and diimide) decrease. The selectivity of nitrogen formation during hydrazine oxidation below $250 \mathrm{~K}$ is controlled by direct reaction processes which leaves the $\mathrm{N}-\mathrm{N}$ bond in hydrazine intact. In this temperature range, hydrogen-oxygen reactions are the dominant mode of interaction with the adsorbed atomic oxygen. Above $250 \mathrm{~K}$, nitrogennitrogen recombination is strongly favored over a broad range of temperatures and coverages. No evidence for nitrogen-oxygen surface reactions was observed even in the presence of excess adsorbed atomic oxygen, clearly suggesting the predominance of $\mathrm{N}$ atom recombination over $\mathrm{N}+\mathrm{O}$ atom surface reaction even in the presence of excess adsorbed atomic oxygen.

\section{References}

[1] J. Prasad and J.L. Gland, Langmuir, submitted.

[2] E.J. Bowen and A.W. Birley, Trans. Faraday Soc. 47 (1951) 580 .

[3] W.I.H. Winning, J. Chem. Soc. 1954 (1954) 926.

[4] J. Prasad and J.L. Gland, Surf. Sci., submitted.

[5] C.T. Campbell and J.M. White, Appl. Surf. Sci. 1 (1978) 347.

[6] P.A. Redhead, Vacuum 12 (1962) 203.

[7] M. Grunze, Surf. Sci. 81 (1979) 603.

[8] B.J. Wood and H. Wise, J. Catal. 39 (1975) 471.

[9] J.L. Gland, G.B. Fisher and G.E. Mitchell, Chem. Phys. I ett. 119 (1985) 90

[10] H.H. Sawin and R.P. Merrill, J. Chem. Phys. 73 (1980) 996.

[11] J. Prasad and J. Gland, J. Am. Chem. Soc., submitted.

[12] F.T. Wagner and T.E. Moylan, Surf. Sci. 191 (1987) 121.

[13] B.E. Gurney and W. Ho, J. Chem. Phys. 87 (1987) 5562.

[14] J. Prasad and J.L. Gland. J. Catal., submitted.

[15] H.H. Sawin, PhD Thesis, Cornell University (1978). 